\title{
SOME EFFECTS OF CORRECTIVE FEEDBACK ON STUDENTS' WRITING
}

\author{
Nirwana AR \\ Faculty of Teachers Training and Education, State University Iqra Buru of Namlea \\ nirwana.arfin@gmail.com \\ Risman Iye \\ Faculty of Sastra Indonesian, State University Iqra Buru of Namlea \\ rismaniye@gmail.com \\ Saidna Zulfiqar bin Tahir \\ Faculty of Teachers Training and Education, State University Iqra Buru of Namlea \\ saidnazulfiqar@gmail.com
}

\begin{abstract}
Several researchers have investigated the effects of corrective feedback (C.F.) on learners' linguistic competence. Still, there was an opportunity to research some effects of WCF on students' linguistic errors by comparing six types of C.F. (direct, indirect, metalinguistic, reformulation, focused, and unfocused C.F.). Single-subject experiment design with alternating treatment design was beneficial in assessing the relative effectiveness of six types of C.F. Linguistic errors categories on vocabulary, language use and mechanics were targeted in C.F. The results of research findings for five weeks study and six students for one group or thirty-six students in the Muhammadiyah University of Makassar showed that direct C.F. had the most significant effect in reducing students' linguistic error and improving students' writing quality in vocabulary, language use and mechanics than the other types of C.F. and direct C.F. also could be suggested for using long-term to the teacher and students at a low intermediate proficiency level.
\end{abstract}

Keywords: writing quality; linguistic errors; corrective feedback, writing instruction

\section{A. INTRODUCTION}

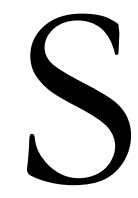

ome researchers investigated the corrective feedback (C.F.) on linguistic accuracies such as Bitchener \& Knoch (2009), Diab (2015), and Sheen (2007). They have investigated direct and indirect writing corrective feedback. Bitchener (2008), Bitchener and Knoch (2010), and Ellis et al. (2008) were among the researchers that have investigated the effects of focus and unfocus C.F. The effects of six types of CF, i.e., direct CF, indirect CF, metalinguistic CF, reformulation CF, focused CF and unfocused CF were investigated by Norman et al. (2011), Ulper \& Cetinkaya (2013), Montgomery \& Baker (2007), Sanavi \& Nemati (2014), and Ellis (2009). They reported different results, which led to the indecisive conclusion about the types of C.F. that could be suggested as the most effective ways for long-term use to learners of English as a foreign language (EFL), especially at the university level. The purpose of providing C.F. is to reduce the students' linguistic errors in writing and to improve the students' writing quality on 
Volume 6, Number 01, June 2020

vocabulary, language use, and mechanics. This study aims to find out some effects of C.F. on students' writing and the types of C.F., which are most effective in reducing students' linguistic errors and improving students' writing quality in vocabulary, language use, and mechanics. The present study investigated some effects of C.F., such as direct, indirect, metalinguistic, reformulation, focused, and unfocused on the writing of the students of the English Department at the Muhammadiyah University of Makassar.

\section{B. REVIEW OF LITERATURE}

\section{Types of corrective feedback}

Ellis (2009) has classified six significant types of WCF, namely: direct, indirect, metalinguistic, focused/unfocused, electronic, and reformulation. Corrective feedback was useful to improve students' writing quality.

Direct C.F. shows the students the correct form or close to the erroneous way, or the provision of the proper linguistic form or structure by the teacher to the student above the linguistic error, such as the crossing out of an unnecessary word, phrase, or morpheme; or the insertion of a missing word, phrase, or morpheme. Indirect C.F. shows the students that they have committed an error without actually correcting it. This could be done by underlining the errors or using cursors to show omissions in the students' text, underlining or circling the error; recording in the margin the number of errors in a given line; or using a code to show where the error has occurred and what type of error it is (Ferris, 2011). Metalinguistic C.F. provides the learners with some forms of explicit comment about the nature of the mistakes they have made. The exact comment takes two correct ways. First, the use of error codes includes abbreviated labels for different kinds of errors placed over the location of the errors in the text or the margin. Second, the exact location of the error may or may not be shown.

Focused C.F. refers to feedback for certain types of errors that the teacher considers essential to correct. When the teacher chooses to fix all of the students' mistakes, it is called unfocused C.F. Electronic feedback is provided using such search engines as Google to assist the students in their writing. This assistance could be accessed utilizing software programs while students write, or it could be used as a form of feedback. Reformulation is a C.F. option similar to the use of concordances in that it aims to provide learners with a resource that they can use to correct their errors but places the responsibility on the students themselves for the final decision about whether and how to fix. 


\section{The effects of C.F. on learners' linguistic accuracy}

There has been evidence that explicit and indirect C.F. has a useful function to influence learners' grammatical accuracy. Bitchener \& Knoch (2009), Diab (2015), and Sheen (2007) have documented that explicit and indirect written corrective feedback (WCF) was more effective than direct and meta-linguistic WCF to increase learners' linguistic accuracy. Bitchener (2008), Bitchener \& Knoch (2010), Ellis et al. (2008) have investigated that WCF is essential in teaching English writing. Direct C.F. could be useful in writing if it is combined with the metalinguistic explanation. On the other hand, Norman et al. (2011), Ulper \& Cetinkaya (2014), Montgomery \& Baker (2007), and Sanavi \& Nemati (2014) have reported that C.F. was needed to improve learners' linguistic accuracy on writing. That reformulation was more effective than other types of WCF (direct, indirect, metalinguistic, and focused/unfocused). Also, Ellis (2009) investigated a typology of written corrective feedback types. He argued that systematically identifying the options was essential for both determining whether WCF was effective and what kind of WCF was most effective.

\section{The effectiveness of WCF for improving students' writing quality}

Writing is one of the productive skills (Harmer, 1991:16). In helping learners achieve the target language, errors should be corrected. This theory of error and error correction is developed by Corder (1974) and George (1972), as cited in Bitchener \& Ferris (2012:7). The purpose of grammatical error correction is to improve student's writing accuracy. Ferris \& Hedgcock (1998) reported that teacher feedback was effective in influencing students' writing. Based on the discussion in the previous section, there seems to be a necessity to investigate further the effects of corrective feedback on EFL students' writing and the types of C.F. that may contribute most to the students' writing accuracy.

\section{METHOD}

\section{Aims}

This study was designed to investigate the effectiveness of writing corrective feedback (WCF). Two research questions were posed as follows:

a) Which types of corrective feedback were most effective in reducing students' linguistic errors?

b) Could corrective feedback improve students' writing quality? 
Volume 6, Number 01, June 2020

\section{Design}

This research employed a quantitative method. This quantitative method was based on a single-subject experimental design using an alternating treatment design. This method was chosen to investigate the comparative effectiveness of six types of WCF (direct, indirect, metalinguistic, reformulation, focused and unfocused C.F.) in reducing students' linguistic error and improving students' writing quality in vocabulary, language use and mechanics by thirty-six participants or six student participants for each group in English Department in the academic year 2015/2016 of Muhammadiyah University Makassar.

\section{Participants}

The study involved 36 of the English Department, Muhammadiyah University of Makassar, academic year 2015/2016. The participants were grouped into six groups, and each group received one type of C.F.

\section{Target Errors for Correction}

This study was limited to linguistic errors in vocabulary, language use, and mechanics. The linguistic errors may be described in more detail as follows:

Language Use

Morphology: Articles (definite/indefinite), possessive case, a third-person singular verb, simple past tense (regular and irregular past tense), past participle, and comparative adjective/adverb.

Syntax

a. Noun phrase: Determiner, nominalization, number, use of the pronoun, use of the preposition.

b. Verb phrase: Omission of the verb, use of progressive form, agreement of subject, and verb.

c. Verb and verb construction

d. Word order

e. Some transformation: Negative transformation, question transformation, three transformations, subordinate clause transformation.

Vocabulary: Choice of diction, word class, and spelling

Mechanics: Use of full stop, use of the comma, use of an apostrophe, quotation marks, use of the semicolon, use of capitalization. 


\section{Data Collection and Analysis}

\section{a. Writing tasks}

The data were obtained through four writing assignments. The first two topics of the four writing jobs required the students to write a descriptive paragraph (text) describing the famous or exciting place in Makassar and Indonesia. The third task asked the students to write a narrative book telling about their inspiring, memorable experience. The last job asked the students to write a story.

Each piece of students' writing was read and evaluated for linguistic errors. Every error was marked as feedback for correction. Six types of feedback were provided following each treatment group, i.e., direct, indirect, metalinguistic, reformulation, focused, and unfocused C.F. After receiving the C.F., the students reviewed the feedbacks. They rewrote their writing based on the C.F. they already received.

\section{b. Linguistic Errors}

The identification of the linguistic errors committed by the students was focused on language use, vocabulary, and mechanics. The frequency of the error occurrences used ratio based on the types of errors. Errors on language use are rationally based on the sentence. For example, the verb phrase error in "They located so far is limited by chalk hill." (They are located ...) was counted as one error and was given corrective feedback. The ratio of the language use error was determined in percentage, i.e., the number of errors divided by the total number of sentences in the essay multiplied by one hundred. Then, the average rate of errors in each group was considered as the total linguistic errors in the article.

Vocabulary errors such as "... is limited by chalk hill" ("... is surrounded by limestone hills") were counted and converted into a percentage, i.e., the number of vocabulary errors divided by the total number of words in the essay multiplied by one hundred. Similarly, errors in mechanics use the total number of words to get the ratio and percentage of the errors.

The following are some samples of each linguistic type of errors. Language use (subject-verb agreement and word order): *Leang sumping bita has a high roof. (should be: Leang sumping bita has a steep roof.) *Nine islands is one of the destinations marine tours in Sinjai district, South Sulawesi. (should be: Nine islands is one of the nautical tour destinations in Sinjai district, south Sulawesi.) Vocabulary (word choice): *The cave is found by Poul Sarassin from swiss when 1922. (should be: Poul Sarassin discovers the cave from swiss in 1922.) Mechanics (capitalization): 
Volume 6, Number 01, June 2020

*Nine islands are one of the destination marine tours in Sinjai district, South Sulawesi. (should be: Nine Island is one of the goal marine tours in Sinjai District, South Sulawesi.)

\section{c. Scoring}

The composite score was used to indicate the linguistic feature quality of the writing. It was the average of the combination of the count on language use (5 - 25), vocabulary 7-20), and mechanics (2-5) (Heaton, 1988) after converting the score into a 0-100 scale. For example, a score of 18 in language use, was saved by a simple formula: earned score (18) divided by maximum score in language use (25) multiplied by 100 . Thus the score was 72 . Finally, the converted scores of the language use, vocabulary, and mechanics were averaged to have the intended composite score.

\section{FINDINGS AND DISCUSSION}

\section{Errors}

The students' errors corrected using different types of feedbacks were language use, vocabulary, and mechanics. The language use errors were counted using the ratio between the number of errors in the writing and the total number of clauses or sentences. For example, the number of such mistakes as subject-verb agreement or verb phrases was five, and the total number of terms or sentences in the essay was 20. The error percentage was five divided by 20

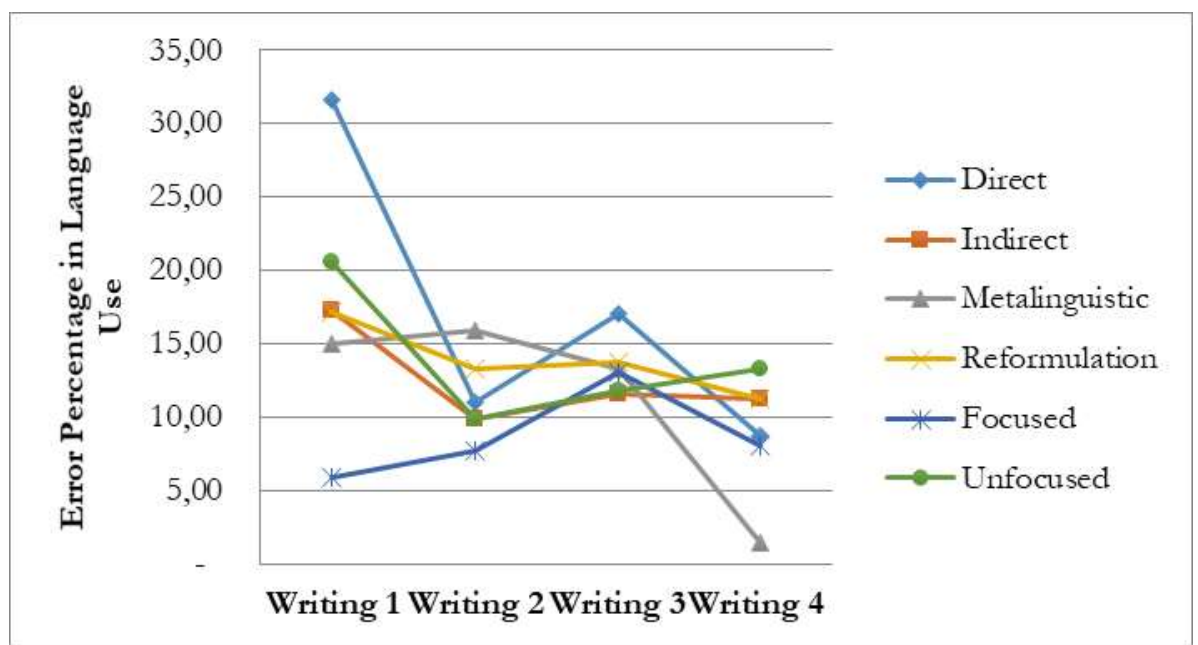

multiplied by 100 , which was $25(25 \%)$.

Figure 1. Error Percentage in Language Use by Writing Tasks and C.F. Types 
Figure 1 shows the trends of language use errors committed by the students from writing task 1 to writing task 4 for each type of C.F. group. Direct C.F. shows quite a dramatic decrease in mistakes, from $31.66 \%$ in essay 1 to $8.79 \%$ in article 4 . Other C.F. groups tend to show similar decreasing trends in their language use errors, but not as sharp as the direct C.F. This indicates that direct C.F. was the most useful feedback in reducing the students' errors in language use. The second most effective C.F. was metalinguistic C.F. showing quite a significant reduction of errors from $14.99 \%$ in essay 1 to $1.46 \%$ in article 4 . In comparison, the least effective was focused C.F., which showed even an increase in language use errors from 5.88\% in essay 1 to $8.06 \%$ in article 4.

Vocabulary errors were counted based on the ratio between the number of errors and the total number of words in the essay. Then, it was converted into a percent (percentage). The highest rate of vocabulary errors $(2.5 \%)$ was found in indirect C.F. in the writing tasks 1 . The errors showed excellent education in the subsequent writing tasks, and finally, in the essay 4, students in the indirect C.F. group made an average of $0.6 \%$ vocabulary errors. The percentage of vocabulary errors of the other C.F. groups seemed to have fluctuated, yet in the last essay, their mistakes were smaller in number than in the first three essays. Focused C.F. showed the least amount of errors in all four pieces. Figure 2 indicates that indirect C.F., focused C.F. and unfocused C.F. has, to some extent, the impact of the vocabulary component of the students writing.

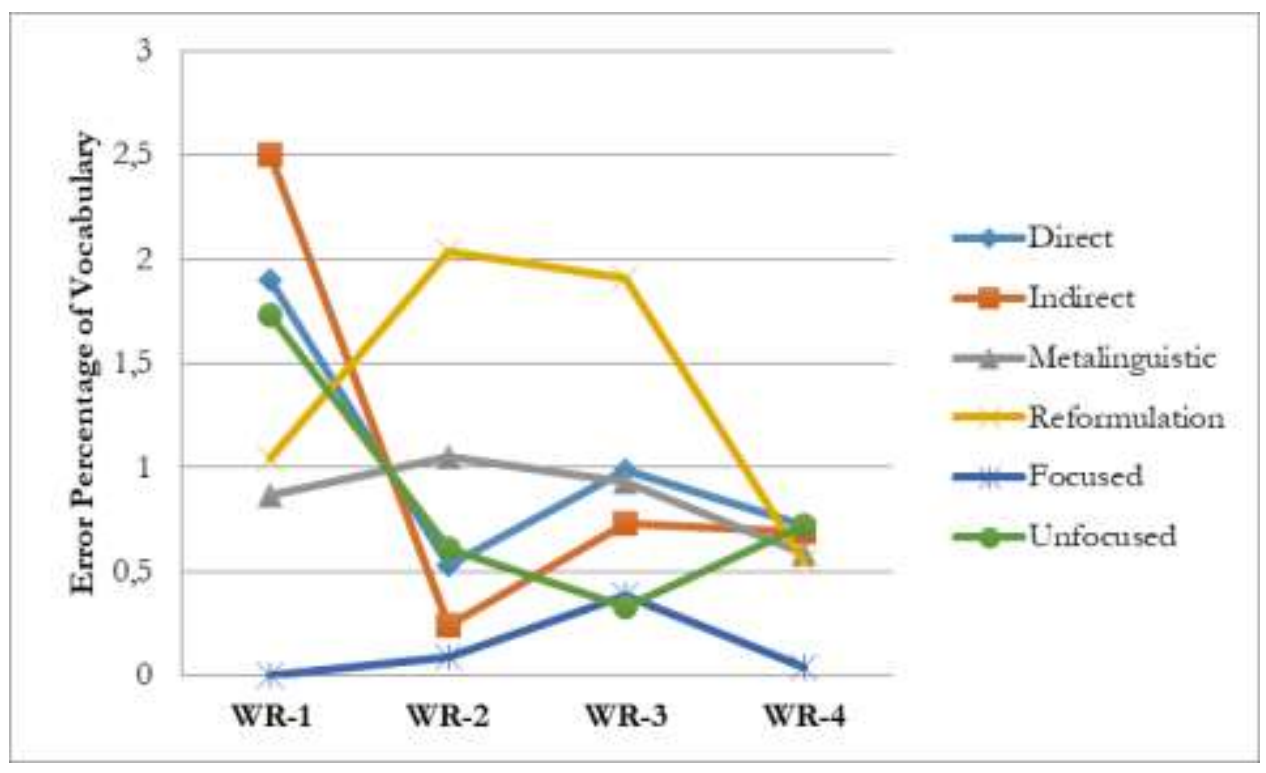

Figure 2. Error Percentage in Vocabulary by Writing Tasks and Types of C.F. 
Errors of mechanics were counted based on the ratio between the number of errors (i.e., spelling, capitalization) and the total number of words or the total number of sentences for punctuation errors. Then, it was converted into a percentage. Figure 3 shows the rate of writing mechanics errors. Regardless of the C.F. types, a similar trend of error reduction is demonstrated

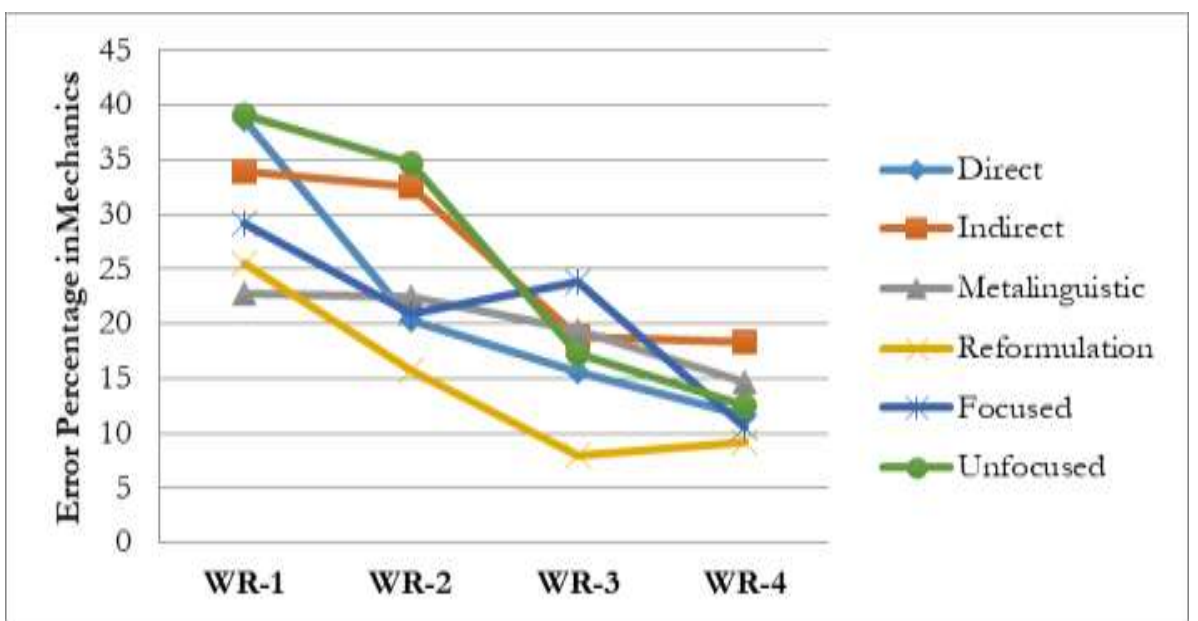

by all C.F. groups across the four writing tasks. The most significant error reduction is found in the essays of students in the unfocused C.F., from 39.16\% in articles 1 to $12.54 \%$ in section 4 , followed by direct C.F. from $38.61 \%$ in column 1 to $11.62 \%$ in essay 4 . In short, each type of corrective feedbacks has, to some extent, a positive effect on the reduction of mechanics errors in the students' writing.

Figure 3. Error Percentage in Mechanics by Writing Tasks and Types of CF

\section{Writing Score}

The evaluation of the students' writing is carried out using parts of Heaton's analytical scoring rubric. Since this study is concerned with the linguistic components of the essay, the evaluation is only given to language use, vocabulary, and mechanics. The other two parts in the rubric, i.e., content and organization, are not included. The scores for each linguistic component

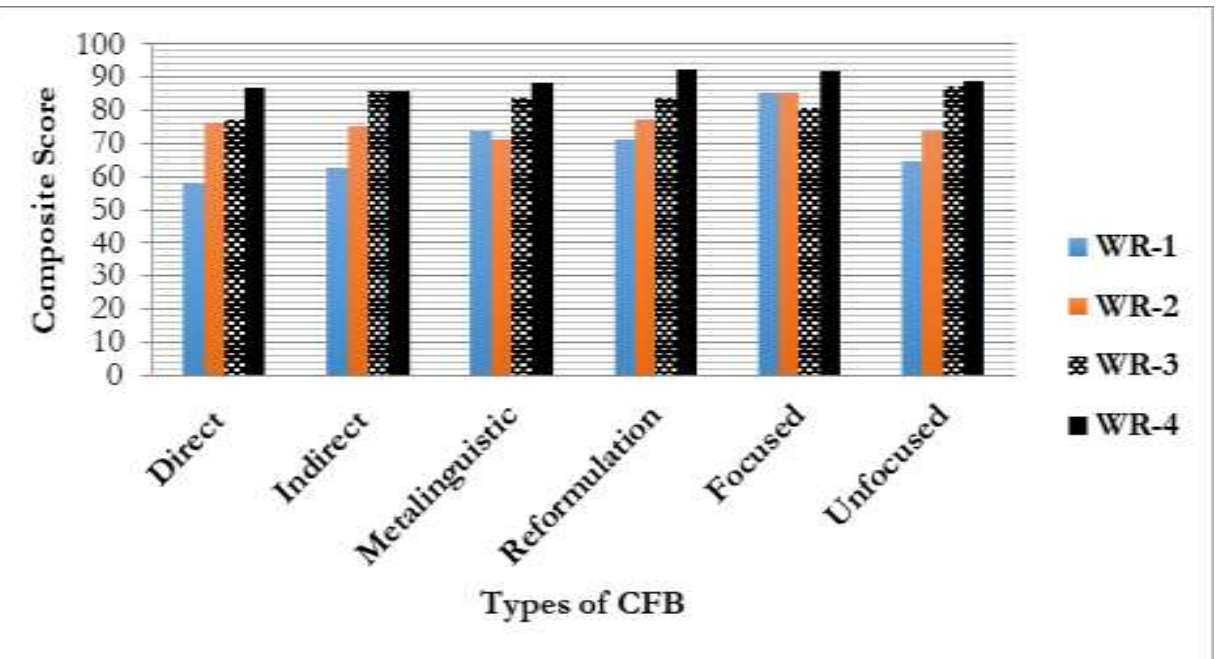


of the essay can be seen in Table 1, and the composite (combined) scores in Figure 4.

Figure 4. Composite Score of the Linguistic Components of the Writing by Types of C.F. and Writing Tasks

Figure 4 shows that the student's scores increase in subsequent writing. The highest score increase (29 points) is found in the direct C.F., i.e., from 58 for essay 1 to 87 in article 4, followed by unfocused C.F. (24 points), indirect C.F. (23 points), and reformulation C.F. (21.33 points). The highest scores gained in essay 4 are 92.33 and 92 by students in reformulation C.F. and focused C.F., respectively. Since the corrective feedbacks enable the students to improve their writing accuracy, which is to reduce errors in the linguistic components of their writing, the quality of the book also enhances, as shown in Figure 4.

Table 1. Errors and Scores of the Students' Writing

\begin{tabular}{|c|c|c|c|c|c|c|c|c|c|}
\hline \multirow{2}{*}{$\begin{array}{l}\text { Corrective } \\
\text { Feedback }\end{array}$} & \multirow{2}{*}{$\begin{array}{l}\text { Linguistic } \\
\text { Features }\end{array}$} & \multicolumn{2}{|c|}{ Writing 1} & \multicolumn{2}{|c|}{ Writing 2} & \multicolumn{2}{|c|}{ Writing 3} & \multicolumn{2}{|c|}{ Writing 4} \\
\hline & & $\%$ Errors & Score & $\%$ Error & Score & $\%$ Error & Score & $\%$ Error & Score \\
\hline \multirow{4}{*}{ Direct } & L-Use & 31.66 & 64 & 11.07 & 84 & 17.04 & 72 & 8.79 & 96 \\
\hline & Vocabulary & 1.9 & 70 & 0.53 & 85 & 0.99 & 80 & 0.72 & 85 \\
\hline & Mechanics & 38.61 & 40 & 20.41 & 60 & 15.64 & 80 & 11.62 & 80 \\
\hline & Comp-Score & & 58 & & 76.33 & & 77.33 & & 87 \\
\hline \multirow{4}{*}{ Indirect } & L-Use & 17.3 & 88 & 9.93 & 96 & 11.6 & 92 & 11.19 & 92 \\
\hline & Vocabulary & 2.5 & 60 & 0.24 & 90 & 0.73 & 85 & 0.69 & 85 \\
\hline & Mechanics & 33.96 & 40 & 32.55 & 40 & 18.77 & 80 & 18.4 & 80 \\
\hline & Comp-Score & & 62.67 & & 75.33 & & 85.67 & & 85.67 \\
\hline \multirow{5}{*}{ Metalinguistic } & & & & & & & & & 10 \\
\hline & L-Use & 14.99 & 92 & 15.95 & 88 & 13.32 & 92 & 1.46 & 0 \\
\hline & Vocabulary & 0.87 & 80 & 1.05 & 65 & 0.93 & 80 & 0.59 & 85 \\
\hline & Mechanics & 22.83 & 60 & 22.47 & 60 & 19.48 & 80 & 14.74 & 80 \\
\hline & Comp-Score & & 77.33 & & 71.00 & & 84.00 & & 88.33 \\
\hline \multirow{5}{*}{ Reformulation } & L-Use & 17.16 & 88 & 13.27 & 92 & 13.8 & 92 & 11.2 & 92 \\
\hline & Vocabulary & 1.04 & 65 & 2.04 & 60 & 1.91 & 70 & 0.55 & 85 \\
\hline & & & & & & & 10 & & 10 \\
\hline & Mechanics & 25.49 & 60 & 15.76 & 80 & 8 & 0 & 9.19 & 0 \\
\hline & Comp-Score & & 71.00 & & 77.33 & & 87.33 & & 92.33 \\
\hline \multirow{5}{*}{ Focused } & L-Use & 5.88 & 96 & 7.71 & 96 & 13.12 & 92 & 8.06 & 96 \\
\hline & & & & & 10 & & & & 10 \\
\hline & Vocabulary & 0 & 100 & 0.09 & 0 & 0.39 & 90 & 0.04 & 0 \\
\hline & Mechanics & 29.26 & 60 & 20.91 & 60 & 23.89 & 60 & 10.61 & 80 \\
\hline & Comp-Score & & 85.33 & & 85.33 & & 80.67 & & 92.00 \\
\hline \multirow{4}{*}{ Unfocused } & L-Use & 20.61 & 84 & 9.91 & 96 & 11.78 & 92 & 13.26 & 92 \\
\hline & Vocabulary & 1.73 & 70 & 0.61 & 85 & 0.33 & 90 & 0.72 & 85 \\
\hline & Mechanics & 39.16 & 40 & 34.7 & 40 & 17.31 & 80 & 12.54 & 89 \\
\hline & Comp-Score & & 64.67 & & 73.67 & & 87.33 & & 88.67 \\
\hline
\end{tabular}




\section{Volume 6, Number 01, June 2020}

The discussion is presented following the research questions and, at the same time, deliberating the answer to the research questions.

1. Which types of corrective feedbacks were most effective in reducing students' linguistic errors?

Based on the data summary of errors presented in Table 1, the researchers try to show the effectiveness of the corrective feedback by comparing the mistakes committed in essay one and faults determined in article four under the assumption that the students have learned from the feedback they received. The reduction of language use errors in percentage can be ordered based on the type of corrective feedback from the greatest to the smallest difference between essay 1 and 4 as follows: direct F.B. (22.87\%), metalinguistic C.F. (13.53\%), unfocused $(7.35 \%)$, indirect C.F. (6.11), and reformulation (5.96\%), while focused C.F. shows an increase of $2.18 \%$.

The decrease of errors in vocabulary can be ordered from indirect CF $(1.81 \%)$, direct CF $(1.18 \%)$, unfocused $(7.35 \%)$, reformulation $(0.45 \%)$, metalinguistic CF $(0.45 \%)$ and focused CF $(0.04 \%)$.

The reduction of errors in mechanics can be ordered from direct C.F. (26.99\%), unfocused $(26.62 \%)$, focused C.F. (18.15\%), reformulation $(16.3 \%)$, indirect C.F. $(15.56 \%)$, and metalinguistic C.F. $(8.09 \%)$.

To summarize, direct C.F. has the most impact on the students' error reduction in language use and mechanics. Thus, corrective feedback improves the grammatical accuracy of the students' writing. This finding is in line with Diab (2015), Sheen (2007) and Ellis et al. (2008). For mechanics error reduction, unfocused C.F. is second to the most effective. For vocabulary error reduction, the most effective corrective feedback is indirect C.F. This finding is relatively the same as Diab (2015) and Sheen (2007), which shows the effects of direct, indirect, and metalinguistic writing corrective feedback (WCF) on learners' grammatical accuracy.

2. Could corrective feedback improve students' writing quality?

The corrective feedback provided in essay one was carefully learned and used by the learners to rewrite the article. It is expected that when working on the subsequent writing tasks, the students will not commit the same errors in language use, vocabulary, and mechanics. Although they cannot ultimately be free of such mistakes, they make errors much less in number. Therefore, the percentage of errors in these language components decreases in their writing. This decreasing percentage of mistakes from the first writing task to the fourth writing task contributes to the quality of the essay. This is evident, as shown in Figure 4. The scores of the students 
writing in the components of language use, vocabulary, and mechanics improve from essay 1 to essay 4. In can be concluded that corrective feedback can enhance the quality of the students' writing, particularly in the components of language use, vocabulary, and mechanics. In other words, the six types of corrective feedback can reduce students' linguistic errors, which, in turn, improve students' writing quality in language use, vocabulary, and mechanics.

This finding is similar to the conclusion by Jokar \& Soyoof (2014), Eslami (2014) and Frear \& Chiu (2015) claiming about the effects of writing corrective feedback (WCF) on learners' grammatical accuracy. Norman et al. (2011), Ulper \& Cetinkaya (2014), Montgomery \& Baker (2007), and Sanavi \& Nemati (2014) the effects of six types of WCF on learners' linguistic accuracy. Bitchener (2008), Bitchener \& Knoch (2010), and Ellis, et al. (2008) have also documented the effects of both focus and unfocused WCF on learners' linguistic accuracy.

Specifically, this study shows slightly different findings. For example, the previous studies, e.g., Bitchener (2008), Bitchener \& Knoch (2010), Ellis et al. (2008) claim that indirect C.F. and reformulation are more effective C.F. in reducing students' linguistic errors than other types of C.F. (direct, metalinguistic, focused, and unfocused) while the present study direct C.F. is more effective in reducing students' linguistic errors than other types of C.F.

The most significant contribution of this research is that students' writing errors, especially errors in linguistic components, can be reduced by providing direct C.F. Direct C.F. could minimize students' linguistic errors and improve students' writing accuracy and quality significantly. It seems that the students can learn better from their mistakes when they are provided with direct correction of the errors. Although other types of corrective feedbacks may also be useful for the students to learn, direct C.F. can be helpful for long-term effects on the student

\section{E. CONCLUSION}

The six types are corrective feedback, namely direct C.F., indirect C.F., metalinguistic C.F., reformulation C.F., focused, and unfocused C.F. can be applied to reduce the linguistic errors in the students' writing. The linguistic errors decrease overtime on their subsequent writing tasks. Direct C.F. is found to be more effective than the other five types of corrective feedback.

The reduction of errors in the students' writing has some impact on the quality of the book, especially in the components of language use, vocabulary, and mechanics. The scores assigned to the students' writing increase from essay 1 to essay 4. It can be concluded that the provision of 
Volume 6, Number 01, June 2020

corrective feedback on the language components of the students' essays improves the quality of the articles.

\section{REFERENCES}

Bitchener, J. (2008). Evidence in support of written corrective feedback in New Zealand. Journal of Second Language Writing, 17, 102-118. DOI:10.1016/j.jslw.2007.11.004

Bitchener, J. \& Ferris, D.R. (2012). Writing corrective feedback in second language acquisition and writing. (New York).

Bitchener. J. \& Knoch, U. (2010). Raising the linguistic accuracy level of advanced L2 writers with written corrective feedback in New Zealand. Journal of Second Language Writing, 19, 207 217. DOI:10.1016/j.jslw.2010.10.002

Corder, S. P. (1974). Error Analysis. In J. P. B. Allen and S. Pit Corder (eds.) Techniques in Applied Linguistics (The Edinburgh Course in Applied Linguistics:3), London: Oxford University Press (Language and Language Learning), pp. 122-154.

Diab, N.M. (2015). Effectiveness of written corrective feedback: Does the type of error and kind of correction matter? in Lebanon. Assessing Writing, 24, 16-34.

Ellis, R. (2009). A typology of written corrective feedback types. ELT Journal, 63 (2), 97-107. DOI:10.1093/elt/ccno23

Eslami. E. (2014). The effects of direct and indirect corrective feedback techniques on EFL students' writing in Iran. Procedia: Social and Behavioral Sciences, 98, 445-452. DOI: 10.1016/j.sbspro. 2014.03.438

Ferris, D.R. (2011). Treatment of Error in Second Language Student. Writing Second Edition. USA. 1.

Ferris, D. \& Hedgcock, J. (1998). Teaching ESL composition. Mahwah, NJ: Laurence Erlbaum Associates.

Frear, D. \& Chiu, Y. (2015). The effect of focused and unfocused indirect written corrective feedback on EFL learners' accuracy in new pieces of writing in the United Arab Emirates. System, 53, 24-34.

George, H.V. (1972). Common errors in language learning. Rowley, Massachusetts. 
Harmer, J., 1991. The Practice of English Language Teaching. New York: Logman Inc.

Heaton, J. (1988). Writing English Language Test. London: Logman Group.

Jokar, M. \& Soyoof, A. (2014). The influence of written corrective feedback on two Iranian learners' grammatical accuracy in Iran. Procedia: Social and Behavioral Sciences, 98, 799-805. DOI: 10.1016/j.sbspro.2014.03.484

Montgomery, J.I. \& Baker, W. (2007). Teacher-written feedback: Student perceptions, teacher self-assessment, and actual teacher performance in the USA. Journal of Second Language Writing, 16, 82-99. DOI:10.1016/j.jslw.2007.04.002

Norman, W., Evans, K., Hartshorn, J. \& Strong-Krause, D. (2011). The efficacy of dynamic written corrective feedback for university-matriculated ESL learners in the USA. System, 39, 229-239. DOI:10.1016/j.system.2011.04.012

Sanayi, R.V. \& Nemati, M. (2014). The effect of six different corrective feedback strategies on Iranian English language learners' IELTS writing task 2 in Iran. SAGE, 1-9 DOI: $10.1177 / 2158244014538271$

Sheen, Y. (2007). The effect of focused written corrective feedback and language aptitude on ESL learners' acquisition of articles in the United States. TESOL Quarterly, 41 (2), 255 - 283.

Ulper, H. \& Cetinkaya, G. (2014). Identifying the students' corrective textual actions towards teachers' feedback in Turkey. Procedia: Social and Behavioral Sciences, 116, 227-230. DOI: 10.1016/j.sbspro.2014.01.19 